\title{
Effects of altitude changes on Doppler flow parameters for uterine, umbilical, and mid-cerebral arteries in term pregnancy: A pilot study
}

\author{
Ayşe Nur Aksoy', Gonca Batmaz², Banu Dane², Suna Kabil Kucurl, Ilay Gözükaral \\ ${ }^{1}$ Department of Obsterics and Gynaecology, Nenehatun Maternity Hospital, Erzurum, Turkey \\ ${ }^{2}$ Department of Obstetrics and Gynaecology, Bezmialem Vakif University Faculty of Medicine, İstanbul, Turkey
}

\begin{abstract}
Objective: We hypothesized that maternal and fetal circulations may be affected by moderately high altitudes. Therefore, we compared the differences in maternal and fetal Doppler flow parameters in women with term pregnancy living at a moderately high altitude (1890 $\mathrm{m}$ in Erzurum) with those of women living at the sea level (31 $\mathrm{m}$ in İstanbul).

Material and Methods: Eighty women ( $n=40$, for each group) with full-term and singleton pregnancies underwent Doppler waveform analysis, and the pulsatility and resistance index values for the uterine, umbilical, and mid-cerebral arteries were recorded. Also, sex, birth, and placental weights during delivery were obtained from the medical records.

Results: Similar mean placental weight values were found at the sea level compared with the moderately high altitude $(p>0.05)$. The mean birth weight values were found to be lower at the moderately high altitude than those at the sea level $(\mathrm{p}<0.05)$. The pulsatility and resistance index values for the umbilical and mid-cerebral arteries were found to be similar between the groups $(p>0.05)$. However, the pulsatility and resistance index values for both the right and left uterine arteries were higher at the sea level than those at moderately high altitude ( $\mathrm{p}<0.05$, for all).

Conclusion: Moderately high altitude does not affect fetal vascular Doppler parameters. However, it appears to increase the uterine artery blood flow bilaterally, and these alterations in the bilateral uterine artery blood flow may be associated with a physiological adaptation to high altitude.

(J Turk Ger Gynecol Assoc 2015; 16: 237-40)
\end{abstract}

Keywords: Doppler, ultrasound, fetus, altitude, pregnancy

Received: 02 July, 2014

Accepted: 30 June, 2015

Available Online Date: 02 November, 2015

\section{Introduction}

Respiratory, cardiovascular, and hematological adaptations (an increase in blood viscosity, a decrease in carbon monoxide diffusion capacity, an increase in cerebral arterial blood flow, a reduction in blood volume, and a decline in cardiac output) occur in individuals living at high and moderate altitudes. These adaptations are associated with the changes in oxygen uptake and transport that occurs in response to hypoxemia $(1,2)$.

The Doppler flow parameters of the umbilical, mid-cerebral, and uterine arteries have been investigated to assess the fetal well-being and maternal risk for preeclampsia (3-5). The altitude was found to be independently associated with the birth weight restriction and adverse perinatal outcomes (6). Moreover, the frequency of preeclampsia, gestational hypertension, and other pregnancy-related complications were reported to be higher in women living at a high altitude (3600 $\mathrm{m})$ than women living at a low altitude $(300 \mathrm{~m})$ (7). Kumtepe et al. (8) demonstrated a greater incidence of eclampsia among women living at high altitudes $(>1500 \mathrm{~m})$.

There are studies in the literature comparing the effect of altitude on maternal and fetal Doppler flow parameters; however, these studies have conflicting results (9-15). For instance, Galan et al. (14) reported no uteroplacental or fetal vascular Doppler velocimetry differences between moderate highlanders and lowlanders, whereas Krampl et al. (11) reported a lower impedance of uterine artery blood flow in women living at a high altitude than at the sea level. We therefore hypothesized that maternal and fetal circulations may be affected by moderately high altitudes. Therefore, we aimed to detect the differences in the pulsatility index (PI) and resistance index (RI) values for uterine, umbilical, and mid-cerebral arteries in women with term pregnancy living at a moderately high altitude (1890 $\mathrm{m}$ in Erzurum) with those of women living at the sea level (31 $\mathrm{m}$ in İstanbul). In addition, we compared the differences in birth and placental weights between moderately high and low altitudes. 


\section{Material and Methods}

This descriptive study was approved by the Ethics Committee of Atatürk University, Medical Faculty, Erzurum, Turkey, and written informed consent was obtained from all participants. Between February 1, 2014 and July 20, 2014, women between 20 and 40 years of age with full-term pregnancies ( $\geq 37$ gestational weeks) admitted to the Obstetric Department of two institutes (Nenehatun Hospital, Erzurum Turkey: 1890 m above the sea level and Bezmialem Vakif University, İstanbul, Turkey: $31 \mathrm{~m}$ above the sea level) for the control were enrolled in this study. Initially, the last menstrual period was questioned, and ultrasonographic evaluation was performed to confirm the gestational age and to detect fetal abnormalities. Patients with a body mass index $\geq 30 \mathrm{~kg} / \mathrm{m}^{2}$, multiple pregnancies, complicated pregnancies (e.g., preeclampsia, fetal malformation, gestational diabetes mellitus, and placenta praevia), smoking, chronic illnesses (e.g., hypertension, diabetes mellitus), and no certain menstrual history were excluded from the study. Moreover, women were excluded if they were not of the ethnic Turkish background and if they did not permanently reside at the altitude.

To minimize the inter-operator variability, all ultrasonographic scans were performed by the same operators at each altitude between 10.00 and 12.00 PM, and three consecutive measurements were calculated in the absence of fetal movements or breathing movements. Ultrasound devices had simultaneous real-time, color-mode, and Doppler-mode capability, and all measurements were performed using the equipment pulse Doppler $5 \mathrm{MHz}$ trans-abdominal probe (Mindray, Schenzen, China and Voluson 730 Pro, GE Healthcare Technologies, Milwaukee, Wisconsin, USA). In all cases, the uterine artery (UA) on each side was visualized at the point just distal to the crossover with the iliac artery. The umbilical artery (UmbA) was examined on a free loop of the umbilical cord, and the midcerebral artery (MCA) was visualized in a transverse axial view of the fetal head. Sociodemographic information (age, body mass index, parity, gestational week) and PI and RI indices for UA, UmbA, and MCA were recorded. In addition, sex, birth, and placental weights during delivery were obtained from the medical records.

A power analysis for this study was calculated based on the work of Galan et al. (14) using Russ Lenth's Power and sample size calculation application (15). We aimed to detect a mean difference between the two groups, at least a 1.5 standard deviation (SD) on Doppler index values. Accordingly, we determined that the number of patients required in every group was 30 , based on the power of $80 \%$ at $5 \%$ significance level.

Data were analyzed using the Statistical Package for the Social Sciences (SPSS) software 12.0 (SPSS Inc., Chicago, Illinois, USA) and expressed as mean $\pm \mathrm{SD} ; \mathrm{p}<0.05$ was considered significant. The Kolmogorov-Smirnov test was used to test the normality of the variables. If data was not normally distributed, the comparisons were determined using Mann-Whitney's U-test. Comparisons were determined using the independent samples t-test when the data was normally distributed, and Fisher's exact test was used to compare the percentage values.
Table 1. Clinical characteristic of patients living at the sea level and moderately high altitude

\begin{tabular}{|l|c|c|c|}
\hline & $\begin{array}{c}\text { Moderately high } \\
\text { altitude group } \\
(\mathbf{n}=40)\end{array}$ & $\begin{array}{c}\text { Sea level } \\
\text { group } \\
(\mathbf{n = 4 0 )}\end{array}$ & $\mathbf{p}$ \\
\hline Age (years) & $28.45 \pm 3.86$ & $30.07 \pm 4.54$ & 0.089 \\
\hline Body mass index $\left(\mathrm{kg} / \mathrm{m}^{2}\right)$ & $29.55 \pm 3.34$ & $29.40 \pm 3.93$ & 0.855 \\
\hline Parity & $2(1-6)$ & $2(1-6)$ & 0.632 \\
\hline $\begin{array}{l}\text { Mean gestational age } \\
\text { (weeks) }\end{array}$ & $38.96 \pm 1.19$ & $39.01 \pm 1.02$ & 0.858 \\
\hline $\begin{array}{l}\text { Gender of fetus } \\
\text { (Female/Male) }\end{array}$ & $26 / 14$ & $28 / 12$ & 0.785 \\
\hline \multicolumn{2}{|l|}{ Data were expressed as mean \pm SD or median (min-max) } \\
\hline
\end{tabular}

Table 2. Comparison of Doppler flow parameters and mean birth and placental weights between the groups

\begin{tabular}{|l|c|c|l|}
\hline & $\begin{array}{c}\text { Moderately high } \\
\text { altitude group } \\
\text { (n=40) }\end{array}$ & $\begin{array}{c}\text { Sea level } \\
\text { group } \\
\mathbf{( n = 4 0 )}\end{array}$ & p \\
\hline Mean birth weight (g) & $3389.87 \pm 331.63$ & $3603.12 \pm 446.90^{*}$ & 0.018 \\
\hline Mean placental weight (g) & $609.90 \pm 78.36$ & $593.86 \pm 8.90$ & 0.389 \\
\hline Right uterine artery PI & $0.67 \pm 0.29$ & $0.93 \pm 0.64^{*}$ & 0.026 \\
\hline Right uterine artery RI & $0.40 \pm 0.09$ & $0.47 \pm 0.08^{*}$ & 0.003 \\
\hline Left uterine artery PI & $0.69 \pm 0.28$ & $0.99 \pm 0.54^{*}$ & 0.003 \\
\hline Left uterine artery RI & $0.43 \pm 0.10$ & $0.51 \pm 0.09^{*}$ & 0.001 \\
\hline Umbilical artery PI & $0.81 \pm 0.27$ & $0.77 \pm 0.16$ & 0.432 \\
\hline Umbilical artery RI & $0.54 \pm 0.10$ & $0.52 \pm 0.73$ & 0.364 \\
\hline Mid-cerebral artery PI & $1.53 \pm 0.63$ & $1.42 \pm 0.39$ & 0.339 \\
\hline Mid-cerebral artery RI & $0.79 \pm 0.29$ & $0.72 \pm 0.10$ & 0.340 \\
\hline $\begin{array}{l}\text { *p<0.05; compared with the moderately high altitude group. } \\
\text { PI: pulsatility index; RI: resistance index }\end{array}$ \\
\hline
\end{tabular}

\section{Results}

During the study period, 120 women (65 in Erzurum and 55 in İstanbul), of whom 90 agreed to participate, met the inclusion criteria for the study. Forty-five women in each group underwent Doppler waveform analysis. Of these, 10 women were lost to follow-up before delivery and were therefore excluded from the study. Thus, 40 women in each group were included in the final statistical analyses. There were no differences in the clinical characteristics between the groups (Table 1). Doppler flow parameters and mean birth and placental weights in the groups are presented in Table 2. The mean placental weight values were similar between the groups ( $p>0.05)$. The mean birth weight values were found to be lower at the moderately high altitude than those at the sea level $(p<0.05)$. Both groups had similar PI and RI values for the umbilical and mid-cerebral arteries ( $p>0.05)$. However, the PI and RI values for both the right and left uterine arteries were higher at the sea level than those at the moderately high altitude ( $p<0.05$, for all) (Table 2). 


\section{Discussion}

It has been known that high altitudes lead to respiratory, cardiovascular, and hematological changes (such as hyperventilation, polycythemia, pulmonary vasoconstriction, and an increase in the systemic blood pressure) in individuals $(1,2)$. In this study, we compared the maternal and fetal Doppler flow parameters in women with term pregnancy living at a moderately high altitude with those of women living at the sea level. We found lower bilateral uterine artery PI and RI values at the moderately high altitude than those at the sea level. However, we found no differences between the groups in terms of Doppler parameters for the umbilical and mid-cerebral arteries. Moreover, we reported lower birth and similar placental weight values at the moderately high altitude compared with those at the sea level. Uterine artery Doppler flow parameters have been used to assess the risk of developing preeclampsia and fetal growth restriction (16-18). The incidence of pregnancy-related complications such as preeclampsia and eclampsia was found to be higher in women living at a high altitude than that in women living at a low altitude $(7,8)$. We observed lower PI and RI indices in both the right and left uterine arteries at the moderately high altitude than those at the sea level. Similar to our results, Krampl et al. (11) reported lower uterine artery blood flow impedance at a high altitude than that at the sea level. In a study by Galan et al. (14), Doppler parameters for the uterine artery were found to be similar between moderately high altitude $(1609 \mathrm{~m})$ and sea level $(40 \mathrm{~m})$. However, the altitude difference was $1859 \mathrm{~m}$ in our study, whereas it was $1569 \mathrm{~m}$ in their study (14). In addition, they were unable to compare the ethnic backgrounds among their study population. On the other hand, our study population was selected from a single type of ethnic population. Nevertheless, the cause for these different Doppler findings in our study is unclear. Julian et al. (13) found a greater uterine artery diameter and volumetric flow at a low altitude than at a high altitude. Moreover, they found an elevation in the maternal circulating vasoconstrictor endothelin relative to the vasodilator nitric oxide metabolite levels at a high altitude. These findings may explain the reason why the uterine artery RI and PI decrease at a high altitude.

We found lower birth weight at a high altitude compared with that at the sea level. In addition, we found similar placental weight values between the groups. Similar to our results, Krampl et al. (19) compared ultrasound fetal size at a high altitude and sea level. They reported smaller fetal biometry measurements and lower estimated fetal weight values at a high altitude than those at the sea level. Furthermore, a decline in the birth weight with an average of $102 \mathrm{~g}$ per $1000 \mathrm{~m}$ elevation was reported by Jensen et al. (20). Consistent with our results, Yung et al. (21) reported a significant reduction in the birth weight in the high-altitude group, and placental weight values were also similar between the groups in their study. Besides, Galan et al. (22) reported that the reduced birth weight of the newborns at a high altitude is the result of a reduction in fetal subcutaneous fat tissue and not lean mass.

It is unclear why a decrease in fetal birth weight occurs at a high altitude without any change in placental weight. A recent study (21) revealed the presence of endoplasmic reticulum stress, protein synthesis inhibition, and slowed proliferation in the placenta in response to chronic hypobaric hypoxia. On the other hand, Keyes et al. (23) reported that both high altitude and hypertensive complications are independently associated with the reduction in the birth weight. In another study (24), a significant increase in the reactive oxygen species production in uterine arteries and pressure-dependent uterine arterial myogenic tone was found in pregnant sheep exposed to highaltitude $(3801 \mathrm{~m})$ hypoxia for 110 days compared with the sea level $(300 \mathrm{~m})$. These changes may contribute to the low birth weight at high altitudes. At the same time, Reshetnikova et al. (25) analyzed 10 normal term placentas each collected at three different altitudinal levels. They found no differences in the villous and capillary surface areas or capillary length; however, they found a significant increase in capillary volume at a high altitude. They concluded that the placenta is capable of adapting to hypobaric hypoxia to increase its functional capacity for gaseous exchange.

Our findings are in agreement with those of Schwartz et al. (9), who studied 42 normal Colorado residents (1600 $\mathrm{m}$ in Denver and $3100 \mathrm{~m}$ in Leadville) longitudinally from 20 to 36 weeks gestation. They found a lowered birth weight at a high altitude than at a moderate altitude, but they reported no significant differences in the Doppler indices of the umbilical and mid-cerebral arteries. Julian et al. (13) found no differences at any time in the umbilical or mid-cerebral arteries Doppler flow parameters at low altitude than high altitude. Indeed, the fetus of pregnant sheep acclimatized to long-term hypoxia had similar increases in the cerebral blood flow and cerebral tissue oxygenation to the fetus at a low altitude (26). Contrary to our results, Krampl et al. (12) observed higher umbilical artery PI values at a high altitude than at the sea level. They suggested that the increase in the viscosity and umbilical artery vasoconstriction due to altered endothelial function and increasing production of vasoconstrictor substances such as endothelin or serotonin or increased placental lipid peroxide production may cause the changes in feto-placental circulation at a high altitude.

Our study has two limitations. First, the same operators performed all Doppler studies, but different ultrasound machines were used in our study. Second, our study has a relatively small patient population.

In conclusion, we found lower birth weight and uterine artery $\mathrm{PI}$ and RI indices at the moderately high altitude than at the sea level. We found similar placental weight values and Doppler parameters for the umbilical and mid-cerebral arteries among the groups. We suggested that altitude appears to increase the uterine artery blood flow bilaterally, and these alterations in bilateral uterine artery blood flow may be associated with a physiological adaptation to high altitudes. Large prospective clinical studies, including placental pathological examination, are required to evaluate the effects of the altitude on maternal and fetal Doppler flow parameters and fetal development.

Ethics Committee Approval: Ethics committee approval was received for this study from the Ethics Committee of Atatürk University, Medical Faculty. 
Informed Consent: Written informed consent was obtained from patients who participated in this study.

Peer-review: Externally peer-reviewed.

Author Contributions: Concept - A.N.A., G.B., B.D.; Design A.N.A., S.K.K., I.G.; Supervision - A.N.A., G.B., I.G.; Resource G.B., S.K.K., I.G.; Materials - A.N.A., G.B., S.K.K.; Data Collection and/or Processing - A.N.A., G.B., S.K.K.; Analysis and/or Interpretation - A.N.A., S.K.K., I.G.; Literature Search - A.N.A., B.D., I.G.; Writing - A.N.A., G.B., S.K.K.; Critical Reviews - A.N.A., B.D., I.G.

Conflict of Interest: No conflict of interest was declared by the authors.

Financial Disclosure: The authors declared that this study has received no financial support.

\section{References}

1. Penaloza D, Arias-Stella J. The heart and pulmonary circulation at high altitudes: healthy highlanders and chronic mountain sickness. Circulation 2007; 115: 1132-46. [CrossRef]

2. Paralika SJ, Paralikar JH. High-altitude medicine. Indian J Occup Environ Med 2010; 14: 6-12. [CrossRef]

3. Kalache KD, Dückelmann AM. Doppler in obstetrics: beyond the umbilical artery. Clin Obstet Gynecol 2012; 55: 288-95. [CrossRef]

4. Hwang HS, Kim YH, Kwon JY, Park YW. Uterine and umbilical artery Doppler velocimetry as a predictor for adverse pregnancy outcomes in pregnant women with anemia. J Perinat Med 2010; 38: 467-71. [CrossRef]

5. Ozeren M, Dinç H, Ekmen U, Senekayli C, Aydemir V. Umbilical and middle cerebral artery Doppler indices in patients with preeclampsia. Eur J Obstet Gynecol Reprod Biol 1999; 82: 11-6. [CrossRef]

6. Grandi C, Dipierri J, Luchtenberg G, Moresco A, Alfaro E. Effect of high altitude on birth weight and adverse perinatal outcomes in two Argentine populations. Rev Fac Cien Med Univ Nac Cordoba 2013; 70: 55-62.

7. Keyes LE, Armaza JF, Niermeyer S, Vargas E, Young DA, Moore LG. Intrauterine growth restriction, preeclampsia, and intrauterine mortality at high altitude in Bolivia. Pediatr Res 2003; 54: 20-5. [CrossRef]

8. Kumtepe Y, Dündar O, Cetinkaya K, Ingeç M. Preeclampsia and eclampsia incidence in the eastern anatolia region of Turkey: the effects of high altitude. J Turk Ger Gynecol Assoc 2011; 12: 26-30. [CrossRef]

9. Schwartz J, Cioffi-Ragan D, Wilson MJ, Julian CG, Beatty B, Moore LG, Galan HL. Little effect of gestation at $3,100 \mathrm{~m}$ on fetal fat accretion or the fetal circulation. Am J Hum Biol 2013; 25: 544-9. [CrossRef]

10. Julian CG, Wilson MJ, Lopez M, Yamashiro H, Tellez W, Rodriguez A, et al. Augmented uterine artery blood flow and oxygen delivery protect Andeans from altitude-associated reductions in fetal growth. Am J Physiol Regul Integr Comp Physiol 2009; 296: 1564-75. [CrossRef]

11. Krampl ER, Espinoza-Dorado J, Lees CC, Moscoso G, Bland JM, Campbell S. Maternal uterine artery Doppler studies at high altitude and sea level. Ultrasound Obstet Gynecol 2001; 18: 578-82. [CrossRef]
12. Krampl E, Lees C, Bland JM, Espinoza Dorado J, Moscoso G, Campbell S. Fetal Doppler velocimetry at high altitude. Ultrasound Obstet Gynecol 2001; 18: 329-34. [CrossRef]

13. Julian CG, Galan HL, Wilson MJ, Desilva W, Cioffi-Ragan D, Schwartz J, Moore LG. Lower uterine artery blood flow and higher endothelin relative to nitric oxide metabolite levels are associated with reductions in birth weight at high altitude. Am J Physiol Regul Integr Comp Physiol 2008; 295: 906-15. [CrossRef]

14. Galan HL, Rigano S, Chyu J, Beaty B, Bozzo M, Hobbins JC, Ferrazzi E. Comparison of low- and high-altitude Doppler velocimetry in the peripheral and central circulations of normal fetuses. Am J Obstet Gynecol 2000; 183: 1158-61. [CrossRef]

15. Lenth RV. (2006). Java Applets for Power and Sample Size [Computer software] Retrieved November 14, 2013. Available from: http://www.stat.uiowa.edu/ rlenth/Power.

16. Papageorghiou AT, Yu CK, Erasmus IE, Cuckle HS, Nicolaides KH. Assessment of risk for the development of pre-eclampsia by maternal characteristics and uterine artery Doppler. BJOG 2005; 112 : 703-9. [CrossRef]

17. Pilalis A, Souka AP, Antsaklis P, Daskalakis G, Papantoniou N, Mesogitis S, Antsaklis A. Screening for pre-eclampsia and fetal growth restriction by uterine artery Doppler and PAPP-A at 11-14 weeks' gestation. Ultrasound Obstet Gynecol 2007; 29: 135-40. [CrossRef]

18. Yazıcı G, Dilek TU, Arslan M, Gülhan S, Özdemir G, Dilek S. Prediction of preeclampsia by identification of early diastolic notch in uterine artery doppler measurements. J Turk Ger Gynecol Assoc 2006; 7: 51-55.

19. Krampl E, Lees C, Bland JM, Espinoza Dorado J, Moscoso G, Campbell S. Fetal biometry at $4300 \mathrm{~m}$ compared to sea level in Peru. Ultrasound Obstet Gynecol 2000; 16: 9-18. [CrossRef]

20. Jensen GM, Moore LG. The effect of high altitude and other risk factors on birthweight: independent or interactive effects? Am J Public Health 1997; 87: 1003-7. [CrossRef]

21. Yung HW, Cox M, Tissot van Patot M, Burton GJ. Evidence of endoplasmic reticulum stress and protein synthesis inhibition in the placenta of non-native women at high altitude. FASEB J 2012; 26: 1970-81. [CrossRef]

22. Galan HL, Rigano S, Radaelli T, Cetin I, Bozzo M, Chyu J, et al. Reduction of subcutaneous mass, but not lean mass, in normal fetuses in Denver, Colorado. Am J Obstet Gynecol 2001; 185: 83944. [CrossRef]

23. Keyes LE, Armaza JF, Niermeyer S, Vargas E, Young DA, Moore LG. Intrauterine growth restriction, preeclampsia, and intrauterine mortality at high altitude in Bolivia. Pediatr Res 2003; 54: 20-5. [CrossRef]

24. Xiao D, Hu XQ, Huang X, Zhou J, Wilson SM, Yang S, Zhang L. Chronic hypoxia during gestation enhances uterine arterial myogenic tone via heightened oxidative stress. PLoS One 2013; 8: e73731. [CrossRef]

25. Reshetnikova OS, Burton GJ, Milovanov AP. Effects of hypobaric hypoxia on the fetoplacental unit: the morphometric diffusing capacity of the villous membrane at high altitude. Am J Obstet Gynecol 1994; 171: 1560-5. [CrossRef]

26. Tomimatsu T, Pena JP, Longo LD. Fetal hypercapnia in high-altitude acclimatized sheep: cerebral blood flow and cerebral oxygenation. Reprod Sci 2007; 14: 51-8. [CrossRef] 